\title{
Interpregnancy interval raise odds of adverse perinatal outcome in high fertility region Mewat, Haryana
}

\author{
Anam ul Haq ${ }^{1 *}$, Meenakshi Lallar1, Shazieya Akhter², \\ Yasir Zahoor Baba ${ }^{3}$, Javid Ahmad ${ }^{3}$, Mir Ashfaq Hamid ${ }^{3}$
}

\begin{abstract}
${ }^{1}$ Department of Obstetrics \& Gynecology, SHKM Govt. Medical College Nalhar, Mewat, Haryana, India
${ }^{2}$ Department of Pathology, Sheri-Kashmir Institute of Medical Sciences, Soura ,Srinagar, Jammu and Kashmir, India

${ }^{3}$ Department of Paediatrics, SHKM Govt. Medical College Nalhar, Mewat, Haryana, India
\end{abstract}

Received: 20 June 2014

Accepted: 5 July 2014

*Correspondence:

Dr. Anam ul Haq,

E-mail: anamulhaq801@gmail.com

(C) 2014 Haq A et al. This is an open-access article distributed under the terms of the Creative Commons Attribution Non-Commercial License, which permits unrestricted non-commercial use, distribution, and reproduction in any medium, provided the original work is properly cited.

\begin{abstract}
Background: Objective of current study was to study association between various interpregnancy intervals and adverse perinatal outcome (preterm birth, low birth weight, small for gestational age) and to come out with optimum interpregnancy interval.

Methods: Retrospective cross sectional study in which 400 meo women (para 2 to para 5) fulfilling inclusion and exclusion criteria having diverse interpregnancy intervals were selected. Statistical analysis was done using SPSS. We used multivariate logistic regression analysis to assess the risk of adverse perinatal outcome.

Results: As compared with infants conceived within a time period of 16 to 48 months after a live birth, infants conceived within 16 months after a live birth had odds ratios of 2.1 (95\% CI 1.3 to 3.5) for low birth weight, 2.2 (95\% CI 1.3 to 3.8) for preterm birth, and 2.3 (95\% CI 1.4 to 3.8) for small size for gestational age; infants conceived more than 48 months after a live birth had odds ratios of 1.88 (95\% CI 1.1 to 3.1), 1.96 (95\% CI 1.1 to 3.4), and 2.08 (95\% CI 1.2 to 3.6) for these three adverse outcomes, respectively; $\mathrm{P}$ value $<0.05$.

Conclusions: We came to conclusion that interpregnancy interval of 16 - 48 months is the optimal interval carrying least risk of adverse perinatal outcomes and both short as well as long interpregnancy intervals are significantly associated with birth of preterm, low birth weight and small for gestational age babies. Counselling regarding optimal interpregnancy interval and methods of contraception can go a long way in reducing adverse perinatal outcome.
\end{abstract}

Keywords: Interpregnancy intervals, Low birth weight, Preterm, Small for gestational age

\section{INTRODUCTION}

Spacing of birth is an important concern significantly effecting the outcome of pregnancy, fetal and maternal morbidity/mortality. Optimal birth spacing ensures multiple health and nutritional benefits for mother and child, helping countries achieve maternal and child health millennium development goals. Adverse perinatal outcome is a trauma for pregnant women and the family. 10 to $15 \%$ of all live births are born preterm. Preterm birth is one that occurs through the end of the last day of the thirty-seventh week $\left(259^{\text {th }}\right.$ day) following onset of the last menstrual period. ${ }^{1}$ Prematurity is the single most important cause of perinatal mortality responsible for nearly half of the cases of congenital neurological disability, including cerebral palsy. ${ }^{2}$ Approximately $38 \%$ of deaths in children under five years of age occur within the first month of life, of which $28 \%$ are attributable to premature birth. ${ }^{3}$ Various respiratory, cardiovascular, haematological, gastrointestinal, central nervous system $\&$ metabolic problems are associated with prematurity. Babies who are born small for their gestational age i.e. birth weight less than $10^{\text {th }}$ percentile for gestational age 
are also at risk of death and various morbidities such as intrauterine fetal demise, perinatal asphyxia, hypoglycaemia, polycythemia, hypothermia and dysmorphology. ${ }^{3}$

Its moral responsibility to inform, educate women regarding association between inappropriate interpregnancy intervals and adverse pregnancy outcomes and to council them for accepting methods of contraception for optimising that interval. Primary prevention of adverse perinatal outcome is a major public health goal and identification of modifiable factors is an essential step to achieve the goal.

In our study we eliminated as many as possible confounding factors for increasing the sensitivity of the results. A hypothetical "critical" interpregnancy interval has been proposed indicating the threshold for significant increases in the prevalence of unfavourable outcomes. This critical interval has varied among published reports, ranging from $<6$ months in developed nations to 18 months or longer in developing countries. ${ }^{4}$

\section{METHODS}

One of district of Haryana, Mewat is a distinct demographic region where practice of contraception is bleak, having almost a homogeneous population with high fertility rate, different interpregnancy intervals and questionable perinatal outcome. Prior to this no such type of study was conducted in this region. This study was conducted in SHKM GMC Nalhar district Mewat, from Septrember 2013 to May 2014, only tertiary care hospital in this district. Four hundred multiparous women delivering in this hospital and fulfilling the inclusion \& exclusion criteria were included in this study.

\section{Inclusion criteria}

Multiparous meo women (para 2 to para 4), in the age group of 16 -35 years delivering a singleton baby having delivered previous full term baby, having a reasonable information \& records of previous \& index pregnancy \& having at least three antenatal visits during the index pregnancy were included in this study.

\section{Exclusion criteria}

- Grand multiparous women (para 5 \& above).

- Women having delivered previous preterm baby.

- Women with multiple gestations.

- Women with history of abortion in between previous delivery and index pregnancy.

- Rh negative women.
- Women with cervical incompetence and anatomical uterine abnormalities.

- Women with chronic medical disorders.

- Women with abnormal placental localization and antepartum haemorrhage during index pregnancy.

- Women who smoke tobacco or who have other forms of addiction.

- Women who have taken teratogenic drugs or have received radiation during index pregnancy.

This was a cross-sectional study in which four hundred cases having diverse interpregnancy intervals were selected to measure association between various interpregnancy intervals and adverse perinatal outcome. Optimal interpregnancy interval carrying the least risk of adverse perinatal outcome was also found. A detailed history was taken from every case regarding name, age, residence, parity, date of most recent previous delivery, date of conception of index pregnancy, history suggestive of any chronic illness, history regarding previous delivery $\&$ index pregnancy, history of any drug intake, radiation exposure or tobacco smoking. Investigations done during pregnancy were reviewed including $\mathrm{Hb} \%$, blood group, and ultrasonography.

Every neonate was weighed with the electronic weighing machine and examined for any congenital anomalies.

Interpregnancy interval was calculated and noted in every case. It was defined as the interval between date of most recent previous delivery and date of conception of index pregnancy; taken as first day of Last Menstrual Period (LMP) or calculated from ultrasonic evaluation in cases where last menstrual period was not known or patient having conceived during lactational amenorrhoea.

Pregnancy outcome was noted in the form of preterm birth, low birth weight or small for gestational age.

Preterm neonate is one that is born before thirty seven completed weeks of gestation calculated from first day of last menstrual period as defined by WHO. ${ }^{6}$ In case where last menstrual period was not known gestational age was estimated by reviewing earliest ultrasonographic report.

Low birth weight was defined as birth weight of $<2500$ gm. ${ }^{2}$

Small for Gestational Age (SGA) was defined as the birth weight less than $10^{\text {th }}$ percentile for the gestational age and was calculated from fetal growth chart based on Indian study. ${ }^{5}$

A proforma was filled up for every case and the results were compiled in the form of a master chart. Appropriate 
statistical methods were applied to analyze the association between interpregnancy intervals and adverse pregnancy outcomes; preterm birth, low birth weight and small for gestational age.

\section{RESULTS}

Patients were distributed into three groups according to their interpregnancy intervals; $<16$ months, $16-48$ months and $>48$ months.

180 patients were in the intermediate interpregnancy group of $16-48$ months, 140 patients in <16 months group and 80 patients in $>48$ months interpregnancy interval group. Intermediate interpregnancy group of $16-$ 48 months constituted $45 \%$ of the total sample size, $<16$ months interpregnancy interval constituted $35 \%$ and $>48$ months interpregnancy interval constituted $20 \%$ of sample size (Table 1).

Table 1: Patient distribution among various IPI groups.

\begin{tabular}{|lll|}
\hline IPI groups & $\begin{array}{l}\text { Number } \\
\text { of cases }\end{array}$ & $\begin{array}{l}\% \text { of total } \\
\text { cases }\end{array}$ \\
\hline$<16$ months & 140 & 35 \\
\hline $16-48$ months & 180 & 45 \\
\hline$>48$ months & 80 & 20 \\
\hline
\end{tabular}

IPI, interpregnancy interval; \%, percentage; <, less than; >, greater than

Total number of preterm deliveries among 400 cases were $35(8.75 \%)$. 17 preterm deliveries in $<16$ months group, 10 preterm deliveries in 16-48 months group and 8 preterm deliveries in $>48$ months interpregnancy interval group. There were $12.14 \%, 5.55 \%$ and $10 \%$ preterm deliveries among women with interpregnancy intervals of $<16$ months, $16-48$ months and $>48$ months respectively. Lowest incidence of preterm deliveries was found among women with interpregnancy interval of 16-48 months and highest number of preterm deliveries took place among women with interpregnancy interval of less than 16 months (Table 2).

Table 2: Number and percentage of preterm births among various IPI groups.

\begin{tabular}{|lllll|}
\hline $\begin{array}{l}\text { IPI groups } \\
\text { (months) }\end{array}$ & $\begin{array}{l}\text { Number } \\
\text { of cases }\end{array}$ & $\begin{array}{l}\text { No. of } \\
\text { preterm } \\
\text { births }\end{array}$ & (\% age) \\
\hline$<16$ & 140 & 17 & 12.14 \\
\hline $16-48$ & 180 & 10 & 5.55 \\
\hline$>48$ & 80 & 8 & 10 \\
\hline $\begin{array}{l}\text { All groups } \\
\text { combined }\end{array}$ & 400 & 35 & 8.75 \\
\hline
\end{tabular}

IPI, interpregnancy interval; \%, percentage; <, less than; >, greater than
Among 17 cases of preterm deliveries <16 months interpregnancy interval group; $5(3.57 \%)$ cases had gestational age (28-32) weeks and $13(9.28 \%)$ cases had gestational age $(33-<37)$ weeks. 10 cases of preterm deliveries within 16-48 months interpregnancy interval group; $2(1.1 \%)$ cases had gestational age (28-32) weeks and $9(5 \%)$ cases had gestational age $(33-<37)$ weeks. 9 cases of preterm deliveries $>48$ months interpregnancy interval group; $2(2.5 \%)$ cases had gestational age (28-32) weeks and $7(8.75 \%)$ cases had gestational age $(33-<37)$ weeks. Early preterm deliveries occurred with highest incidence among women with interpregnancy interval of $<16$ months (Table 3).

Table 3: Distribution and percentage of two categories of preterm births among various IPI groups.

\begin{tabular}{|lllll|}
\hline $\begin{array}{l}\text { IPI } \\
\text { groups } \\
\text { (months) }\end{array}$ & $\begin{array}{l}\text { No. of } \\
\text { Cases }\end{array}$ & $\begin{array}{l}\text { Ges. age } \\
<37 \text { wks. } \\
(\%)\end{array}$ & $\begin{array}{l}\text { Ges. age } \\
28-32 \text { wks. } \\
(\%)\end{array}$ & $\begin{array}{l}\text { Ges. age } \\
33-<37 \\
\text { wks. }(\%)\end{array}$ \\
\hline$<16$ & 140 & $17(12.14)$ & $5(3.57)$ & $13(9.28)$ \\
\hline $16-48$ & 180 & $10(5.55)$ & $2(1.1)$ & $9(5)$ \\
\hline$>48$ & 80 & $9(11.25)$ & $2(2.5)$ & $7(8.75)$ \\
\hline
\end{tabular}

IPI, interpregnancy interval; <, less than; >, greater than; Ges., gestational

Among 400 cases $42(10.5 \%)$ were born lowbirth weight babies. Likelihood of low-birth weight was 20 (14.28\%) cases among <16 months, $13(7.22 \%)$ cases among 16-48 months and $9(11.25 \%)$ cases among $>48$ months interpregnancy interval group. Maximum number of low birth weight babies were born to women with interpregnancy interval of $<16$ months, lowest incidence with interpregnancy interval of 16-48 months (Table 4).

Table 4: Number and percentage of $\mathrm{LBW}$ babies among various IPI groups.

\begin{tabular}{|llll|}
\hline $\begin{array}{l}\text { IPI groups } \\
\text { (months) }\end{array}$ & $\begin{array}{l}\text { No. of } \\
\text { cases }\end{array}$ & $\begin{array}{l}\text { LBW } \\
\text { babies }\end{array}$ & $\begin{array}{l}\text { Percentage } \\
(\%)\end{array}$ \\
\hline$<16$ & 140 & 20 & 14.28 \\
\hline $16-48$ & 180 & 13 & 7.22 \\
\hline$>48$ & 80 & 9 & 11.25 \\
\hline $\begin{array}{l}\text { All groups } \\
\text { combined }\end{array}$ & 400 & 42 & 10.5 \\
\hline
\end{tabular}

LBW, low birth weight

Among 20 cases of low birth weight babies < 16 months interpregnancy interval group; $9(45 \%)$ cases were preterm and $11(55 \%)$ cases were term low birth weight babies. 13 cases of low birth weight babies within (1648) months interpregnancy interval group; 5 (38.46\%) cases were preterm and $8(61.53 \%)$ cases were term low birth weight babies. 9 cases of low birth weight babies $>48$ months interpregnancy interval group; $4(44.44 \%)$ cases were preterm and $5(55.55 \%)$ cases were term low birth weight babies. Overall preterm low birth weight babies and term low birth weight babies constituted 
$42.85 \%$ and $57.14 \%$ of total low birth weight babies respectively (Table 5).

Table 5: Number of preterm-LBW and term LBW babies and their percent contribution towards total LBW babies.

\begin{tabular}{|c|c|c|c|c|}
\hline $\begin{array}{l}\text { IPI groups } \\
\text { (months) }\end{array}$ & $\begin{array}{l}\text { Number } \\
\text { of cases }\end{array}$ & $\begin{array}{l}\text { LBW } \\
\text { babies } \\
(\%)\end{array}$ & $\begin{array}{l}\text { Preterm } \\
\text { LBW ( } \% \\
\text { of total } \\
\text { LBW) }\end{array}$ & $\begin{array}{l}\text { Term } \\
\text { LBW (\% } \\
\text { of total } \\
\text { LBW) }\end{array}$ \\
\hline$<16$ & 140 & $\begin{array}{l}20 \\
(14.28)\end{array}$ & $\begin{array}{l}9 \\
(45)\end{array}$ & $\begin{array}{l}11 \\
(55)\end{array}$ \\
\hline $16-48$ & 180 & $\begin{array}{l}13 \\
(7.22)\end{array}$ & $\begin{array}{l}5 \\
(38.46)\end{array}$ & $\begin{array}{l}8 \\
(61.53)\end{array}$ \\
\hline$>48$ & 80 & $\begin{array}{l}9 \\
(11.25)\end{array}$ & $\begin{array}{l}4 \\
(44.44)\end{array}$ & $\begin{array}{l}5 \\
(55.55)\end{array}$ \\
\hline $\begin{array}{l}\text { All groups } \\
\text { combined }\end{array}$ & 400 & $\begin{array}{l}42 \\
(10.5)\end{array}$ & $\begin{array}{l}18 \\
(42.85)\end{array}$ & $\begin{array}{l}24 \\
(57.14)\end{array}$ \\
\hline
\end{tabular}

Among 400 cases 40 (10\%) were born small for gestational age. Likelihood of small for gestational age were $19(13.57 \%)$ cases among < 16 months, $12(6.66 \%)$ cases among 16-48 months and $9(11.25 \%)$ cases among $>48$ months interpregnancy interval group. Maximum number of small for gestational aged babies were born to women with interpregnancy interval of $<16$ months, lowest incidence with interpregnancy interval of 16-48 months (Table 6).
Table 6: Number and percentage of SGA babies among various IPI groups.

\begin{tabular}{|llll|}
\hline $\begin{array}{l}\text { IPI groups } \\
\text { (months) }\end{array}$ & $\begin{array}{l}\text { No. of } \\
\text { cases }\end{array}$ & $\begin{array}{l}\text { SGA } \\
\text { babies }\end{array}$ & $\begin{array}{l}\text { Percentage } \\
(\%)\end{array}$ \\
\hline$<16$ & 140 & 19 & $13.57 \%$ \\
\hline $16-48$ & 180 & 12 & $6.66 \%$ \\
\hline$>48$ & 80 & 9 & $11.25 \%$ \\
\hline $\begin{array}{l}\text { All groups } \\
\text { combined }\end{array}$ & 400 & 40 & $10 \%$ \\
\hline
\end{tabular}

SGA, Small for gestational age

Women with interpregnancy interval of $<16$ months and $>48$ months as compared with women with interpregnancy interval of 16-48 months were found to be at increased risk for preterm birth, Odds ratio of $2.1(95 \%$ CI of 1.2-3.7) and odds ratio of 1.96 (95\% CI of $1.1-3.5)$ respectively; $\mathrm{p}$ value $<0.05$. Association for preterm birth of gestational age 28-32 weeks was found to be more strong, odds ratio of 4.1 (95\% CI 1.3-13.6) and 3.6 (95\% CI 1.02-13.3) for interpregnancy interval of $<16$ months and $>48$ months, respectively. This indicates that women with interpregnancy interval of $<16$ months and $>48$ months were more likely to give birth to babies with lesser gestational age as compared to women with interpregnancy interval of 16-48 months.

Table 7: Adjusted odds ratios (95\% confidence intervals) for the associations between interpregnancy interval and adverse perinatal outcomes.

\begin{tabular}{|c|c|c|c|c|c|}
\hline \multirow[t]{2}{*}{$\begin{array}{l}\text { Pregnancy } \\
\text { Outcome }\end{array}$} & \multicolumn{2}{|c|}{$<16$ months $($ no=280) } & \multirow{2}{*}{$\begin{array}{l}16-48 \text { months } \\
\text { (no=510) } \\
\text { No. }(\%)\end{array}$} & \multicolumn{2}{|c|}{$>48$ months $\left(n_{0}=210\right)$} \\
\hline & No. (\%) & OR (95\% CI) & & No. (\%) & OR (95\% CI) \\
\hline \multicolumn{6}{|l|}{ Preterm birth } \\
\hline Total (<37wk) & $7(12.14)$ & $2.1(1.2-3.7)$ & $10(5.55)$ & $9(11.25)$ & $1.96(1.1-3.5)$ \\
\hline $28-32 w k$ & $5(3.57)$ & $4.1(1.3-13.6)$ & $2(1.1)$ & $2(2.5)$ & $3.6(1.02-13.3)$ \\
\hline$>32-<37 w k$ & $13(9.28)$ & $1.9(1.1$ & $9(5)$ & $7(8.75)$ & $1.6(0.9-3.09)$ \\
\hline \multicolumn{6}{|c|}{ Low birth weight babies } \\
\hline Total LBW babies & $20(14.28)$ & $2.1(1.4-3.5)$ & $13(7.22)$ & $9(11.25)$ & $1.87(1.1-3.1)$ \\
\hline Preterm LBW babies & $9(45)$ & $2.7(1.2-5.3)$ & $5(38.46)$ & $4(44.44)$ & $2.1(0.9-4.8)$ \\
\hline Term LBW babies & $11(55)$ & $1.8(1.1-3.2)$ & $8(61.53)$ & $5(55.55)$ & $1.5(0.9-3.2)$ \\
\hline \multicolumn{6}{|c|}{ Small for gestational age babies (SGA) } \\
\hline SGA babies & $19(13.57)$ & $2.4(1.4-3.9)$ & $12(6.66)$ & $9(11.25)$ & $2.08(1.2-3.7)$ \\
\hline
\end{tabular}

OR, odds ratio; CI, confidence interval

Women with interpregnancy interval of $<16$ months and $>48$ months as compared with women with interpregnancy interval of $16-48$ months were found to be at increased risk for low birth weight babies, OR 2.1 $(95 \%$ CI $1.4-3.5)$ and OR $1.8 \quad(95 \%$ CI $1.1-3.2)$ respectively; $\mathrm{P}$ value $<0.05$. We observed a stronger association between Preterm low birth weight babies and short (<16 months) interpregnancy interval, OR 2.7 (95\% CI 1.2-5.3). 
There is statistically significant association between short (<16 months) and long (>48 months) interpregnancy interval and small for gestational age babies. Short interpregnancy interval (<16 months) OR 2.4 (95\% CI 1.4-3.9); and long interpregnancy interval (>48 months) OR 2.08 (95\% CI 1.2-3.7) (Table 7).

\section{DISCUSSION}

In our study we aimed at knowing whether there was any statistically significant association between interpregnancy intervals and adverse perinatal outcomes. Adverse perinatal outcome is a bad dream for pregnant women and the family.

We worked on the hypothesis that intermediate interpregnancy interval of 16-48 months carried the lowest risk of adverse perinatal outcome. We compared short and long interpregnancy intervals with intermediate interval of 16-48 months for calculation of odds ratio and $95 \%$ confidence interval.

Lower incidence of preterm, low birth weight and small for gestational age babies in our study as compared to general population can be explained by the fact that common confounding factors known to be associated with these adverse perinatal outcomes were excluded from this study.

As compared with infants conceived within a time period of 16 to 48 months after a live birth, infants conceived within 16 months after a live birth had odds ratios of 2.1 (95\% CI 1.3 to 3.5) for low birth weight, 2.2 (95\% CI 1.3 to 3.8 ) for preterm birth, and 2.3 (95\% CI 1.4 to 3.8 ) for small size for gestational age; infants conceived more than 48 months after a live birth had odds ratios of 1.88 (95\% CI 1.1 to 3.1), 1.96 (95\% CI 1.1 to 3.4), and 2.08 (95\% CI 1.2 to 3.6) for these three adverse outcomes, respectively; $\mathrm{P}$ value $<0.05$. There are various studies that are consistent with our study. ${ }^{6-10}$

The mechanism of putative adverse effects of short interpregnancy interval has not been determined. A plausible explanation is maternal nutritional depletion hypothesis. ${ }^{11,12}$ According to this hypothesis close succession of pregnancies and periods of lactation worsen the mother's nutritional status which may not be clinically evident. There is not adequate time for the mother to recover from the physiological stresses of preceding pregnancy before she is subjected to the stresses of the next pregnancy. This results in depletion of maternal nutrient stores with the subsequent increased risk of adverse perinatal outcome. The folate depletion hypothesis claims that maternal serum and erythrocyte concentration of folate decreases from fifth month of pregnancy onwards and remains so for fairly long time after delivery. ${ }^{13}$ Women who become pregnant before folate restoration is complete have increased risk of IUGR, preterm birth and low birth weight due to folate insufficiency.
It is largely unknown why a long interpregnancy interval is associated with adverse perinatal outcomes. We offer two hypotheses to explain the association. ${ }^{14}$ One is that pregnancy may help mothers to gain growth-supporting capacities (such as increased uterine blood flow and other physiological and anatomical adaptation of reproductive system). After delivery those capacities may gradually decline and physiological characteristics may become similar to primigravida if interpregnancy interval is long. This hypothesis is supported by findings that birth primigravida women were associated with higher risks of adverse outcomes as compared to second birth with interpregnancy interval of 18-59 months. Another possibility is that metabolic and anatomical factors that we did not measure, may cause both delayed fertility and adverse perinatal outcome. ${ }^{14}$

We came to conclusion that interpregnancy interval of 16-48 months is the optimal interval carrying the least risk of adverse perinatal outcomes in a homogeneous population of mewat region and that both short as well as long interpregnancy intervals are significantly associated with the birth of preterm, low birth weight and small for gestational age babies and a simple counselling regarding optimal interpregnancy interval and methods of contraception can go a long way in reducing adverse perinatal outcome thus reducing burden and cost on the society and health care system.

\section{ACKNOWLEDGEMENTS}

I am thankful to our HOD; ass prof. S. P. Singh who has always been a source of inspiration to all of us. His zeal for medical research has been and will always be a continuous source of inspiration for me.

I am thankful to my teachers Dr. Divya Mangla, Dr. Prachi. They never asserted bossism that is what makes them more respectable. I shall always remain indebted to them a lifetime for their efforts to accomplish this work.

I express my sincere thanks to Dr. Jyoti Malik who constantly helped me at all stages of the study.

Funding: No funding sources

Conflict of interest: None declared

Ethical approval: The study was approved by the hospital ethics committee

\section{REFERENCES}

1. Kimberly G. Lee, John P. Cloherty. Identifying the high risk newborn. In: John P. Cloherty et al., eds. Manual of Neonatal Care. 5th ed. Philadelphia: Lippincott Williams \& Wilkins, 2004: 45-50.

2. Goldenberg RL, Rouse DJ. Prevention of premature birth. N Engl J Med. 1998;339:313-20.

3. Barbare J. Stoll, Ira Adams-Chapman. The high risk infant. In: Robert M. Kliegman et al., eds. Nelson Text Book of Paediatrics. 18th ed. US: Elsevier Science Health Science Division; 2007: 702-705. 
4. Rawlings JS, Rawlings VB, Read JA. Prevalence of LBW and preterm delivery in relation to the interval between pregnancies among white and black women. N Engl J Med. 1995;332:69-74.

5. OP Ghai. Newborn infant. In: OP Ghai, Vinod K. Paul, Arvind Bagga, eds. Text Book of Paediatrics. 6th ed. New Delhi: CBS Publisher; 2008: 136.

6. Neel NR, Alvarez JO. Risk factors of fetal malnutrition in a group of Guatemalan mothers and neonates. Bol Oficina Sanit Panam. 1991;110:93107.

7. Fikree FF, Berendes HW. Risk factors of term intrauterine growth retardation: a community-based study in Karachi. Bull WHO.1994;72:581-7.

8. Sener T, Gurel SA, Gurel H. Risk factors associated with small for gestational age infants in a Turkish population. J Matern Fetal Invest. 1997;7:145-51.

9. Deshmukh JS, Motghare DD, Zodpey SP, Wadhva Sk. Low birth weight and associated maternal factors in an urban area. Indian Paediatr. 1998;35:33-6.

10. Al Jasmi F, Al Mansoor F, Al Sheiba. Effect of interpregnancy interval on risk of spontaneous preterm birth in Emirati women, United Arab Emirates. Bull WHO. 2002;80:871-5.

11. Caan B, Horgen DM. Benefits associated with WIC supplemental feeding during the interpregnancy interval. Am J Clin Nutr. 1987;45:29-41.

12. Winkvist A, Rasmussen KM. A new definition of maternal depletion syndrome. Am J Public Health. 1992;82:691-4.

13. Manon Van Eijsden. Association between short interpregnancy intervals and term birth weight. Am J Clin Nutr. 2008;88(1):147-53.

14. Bao-Ping Zhu, Robert T. Rolfs, Barry E. Nangle. Effect of the interval between pregnancies on perinatal outcome. N Engl J Med. 1999;340(80):58994.

DOI: $10.5455 / 2320-1770 . i j r \operatorname{cog} 20140934$

Cite this article as: Haq A, Lallar M, Akhter S, Baba YZ, Ahmad J, Hamid MA. Interpregnancy interval raise odds of adverse perinatal outcome in high fertility region Mewat, Haryana. Int J Reprod Contracept Obstet Gynecol 2014;3:598-603. 